\title{
IDENTIFICATION AND ANALYSIS OF MAJOR ELEMENTS IN INDONESIAN HERBAL MEDICINE USING LASER-INDUCED PLASMA SPECTROSCOPY
}

\author{
A.Khumaeni", B.S. Hartadi, A.Y. Wardaya, H. Sugito and W.S. Budi \\ Department of Physics, Faculty of Science and Mathematics, Diponegoro University, \\ J1. Prof. Soedharto, S.H., Tembalang 50275, Semarang, Indonesia \\ *E-mail: khumaeni@fisika.fsm.undip.ac.id
}

\begin{abstract}
Identification and analysis of elements in the herbal medicine have been successfully made by using Nd:YAG laserinduced breakdown spectroscopy. The herbal samples used in this study were Asam urat and flu tulang and Bunga naga medicines. Experimentally, a fundamental Nd:YAG laser was focused on the sample surface to induce a luminous plasma at a reduced pressure of $1333 \mathrm{~Pa}$. The plasma was then sent into the spectrometer to obtain the atomic emission spectrum. The result shows that several atomic lines have been successfully detected including $\mathrm{C}$, $\mathrm{Mg}, \mathrm{Mg}, \mathrm{Fe}, \mathrm{Ca}, \mathrm{Al}$, and $\mathrm{H}$. Those lines represent the major and minor elements in the herbal medicines, which are very beneficial for a human being. A comparative study has also been made using an x-ray diffraction technique. The result confirmed that those mentioned elements have been also detected.
\end{abstract}

Keywords: Herbal Medicine, Laser-induced Breakdown Spectroscopy, Plasma Spectroscopy.

(C) RASĀYAN. All rights reserved

\section{INTRODUCTION}

Recently, many kinds of herbal medicine (with and without brand and quality assurance) are overwhelmingly available in the local market, especially in Indonesia. Herbal medicine contains macro and micronutrients, which are beneficial for the human body such as sodium $(\mathrm{Na})$, calcium $(\mathrm{Ca})$, potassium $(\mathrm{K})$, magnesium $(\mathrm{Mg})$, iron $(\mathrm{Fe})$, and zinc $(\mathrm{Zn})$. Therefore, identification and analysis of elements in herbal medicine are urgently needed.

Various methods have been developed for the analysis of herbal medicine. Flame atomic spectroscopy, Atomic absorption spectroscopy (AAS), Inductively coupled plasma atomic emission spectroscopy (ICPAES) and have been employed by Qing-hua et al. and Ghani et al. for the detection and analysis of elements in herbal medicine.$^{1-4}$ However, those techniques have several drawbacks. Namely, for AAS, it only permits identification of one element within one acquisition. The other is that the sample should be prepared in the form of liquid during the experiment, which is a very delicate sample preparation. Finally, both systems are high-cost, which influences the price of data acquisition.

Laser-induced breakdown spectroscopy (LIBS) is an atomic spectroscopic technique, which can be used to perform analysis qualitative and quantitatively. ${ }^{5-8}$ In this technique, a Nd:YAG laser is generally used to induce a plasma. The plasma is then sent into the optical multichannel analyzer to obtain an emission spectrum, which contains elements from the sample target. This technique has been employed for various kinds of samples in different forms such as solids, liquids, and gases. However, identification and analysis of elements in herbal medicine by using this technique are still very rare and especially for Indonesian herbal medicine, no report has been made by using LIBS technique.

In this work, identification and analysis of Indonesian herbal medicine were made by using LIBS utilizing pulse Nd:YAG laser. The samples used are Asam urat and Flu tulang and Bunga naga herbal medicine. The results informed that those medicines contain major and mineral elements, which is important for the human being. A comparative study was also made using the XRD technique to confirm the elements contained in herbal medicine.

Rasayan J. Chem., 13(2), 898-902(2020)

http://dx.doi.org/10.31788/RJC.2020.1325592

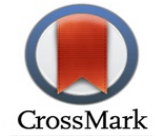


RASĀYAN J. Chem.

Vol. 13 | No. 2 |898 - 902| April - June | 2020

\section{EXPERIMENTAL}

Samples used in this work were Asam urat dan Flu tulang and Bunga naga herbal medicines, which were commercially available in the local market in Indonesia. Before the experiment, the samples were prepared in the form of a pellet. Figure-1 illustrates the setup in this work. A pulse Nd:YAG laser (1064 $\mathrm{nm}, 10 \mathrm{~Hz}, 150 \mathrm{~mJ})(2)$ was operated and controlled by a computer (1). The laser beam was directed by a silver mirror (3) and focused by quartz lens (4) to a sample surface placed in a chamber (5) to produce a plasma. The plasma was then sent into a spectrometer (Michelle 5000) (6) to obtain an emission spectrum. During the experiment, an environmental pressure in the chamber was set at $1333 \mathrm{~Pa}$ to obtain an optimum spectrum.

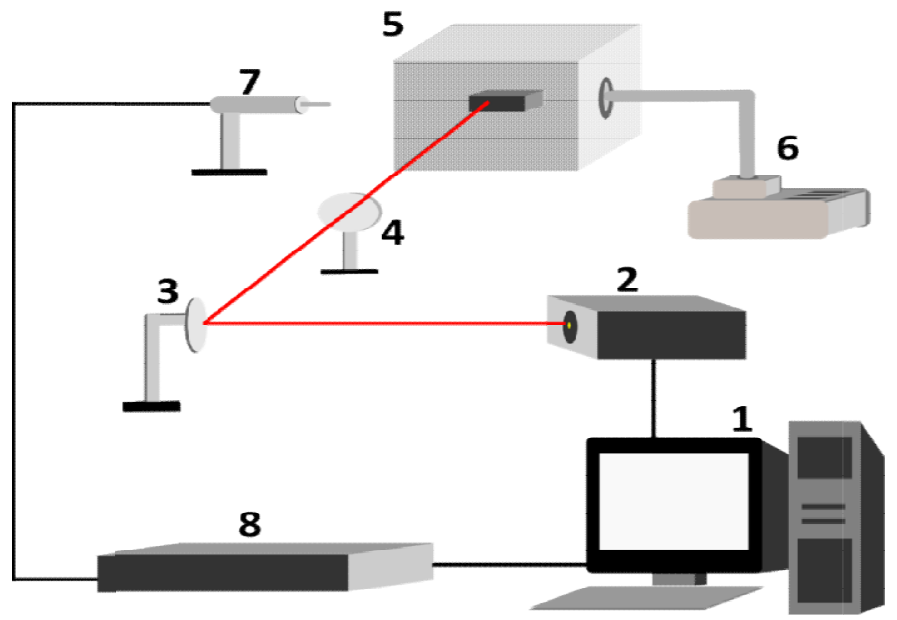

Fig.-1: The Experimental Setup used in this Study

A comparative study was made using the XRD technique to confirm the emission spectrum of $\mathrm{Ca}$, which is detected by using the LIBS technique used in this study.

\section{RESULTS AND DISCUSSION}

First, identification and analysis of the emission spectrum from the sample target were made by using the LIBS technique. Figure-2 shows the atomic spectrum obtained from the Asam urat dan Flu tulang herbal medicine. The energy laser used in this work was $54 \mathrm{~mJ}$ and the pressure was set at $1333 \mathrm{~Pa}$. It can be seen that the spectrum has many discrete emission lines with high emission intensity and low background emission. The law background emission shown in the spectrum certified that the plasma has a low density of electrons, which contributes to the continuous emission due to Bremsstrahlung effect. Emission atomic lines detected correspond to the wavelength of neutral C I at $247.8 \mathrm{~nm}$, ionic $\mathrm{Mg}$ II at $279.6 \mathrm{~nm}$, neutral Al I at $308.2 \mathrm{~nm}$, neutral Fe I at $309.2 \mathrm{~nm}$, ionic $\mathrm{Ca}$ at $393.3 \mathrm{~nm}$ and $396.8 \mathrm{~nm}$, neutral Al I at $394.1 \mathrm{~nm}$ and $396.1 \mathrm{~nm}$, neutral $\mathrm{Ca} \mathrm{I}$ at $422.7 \mathrm{~nm}$, neutral $\mathrm{H} \mathrm{I}$ at $656.3 \mathrm{~nm}$, and neutral $\mathrm{O} \mathrm{I}$ at $777.7 \mathrm{~nm}$. Those detected lines certified that the Asam urat and Flu tulang herbal medicine contains major elements of $\mathrm{C}$, $\mathrm{Mg}, \mathrm{Al}, \mathrm{Fe}, \mathrm{Ca}, \mathrm{H}$, and $\mathrm{O}$. Carbon $(\mathrm{C}), \mathrm{H}$, and $\mathrm{O}$ elements always contain in the herbal medicine because the herbal is an organic material, which is rich on $\mathrm{C}, \mathrm{H}, \mathrm{O}$ elements. Composition of elements, their wavelengths and intensities obtained from the Asam urat and Flu tulang herbal medicine are summarized in Table-1.

Figure-3 shows the emission spectrum taken from the Bunga naga herbal medicine. The spectrum is almost similar to the spectrum obtained from the Asam urat and Flu tulang herbal medicine. Namely, emission lines of $\mathrm{C}, \mathrm{Mg}, \mathrm{Al}, \mathrm{Fe}, \mathrm{Ca}, \mathrm{H}$, and $\mathrm{O}$ are detected at $247.8 \mathrm{~nm}, 279.6 \mathrm{~nm}, 308.2 \mathrm{~nm}, 309.2 \mathrm{~nm}$, $393.3 \mathrm{~nm}$ and $396.8 \mathrm{~nm}, 656.3 \mathrm{~nm}$, and $777.7 \mathrm{~nm}$, respectively. The other element was detected at 589.1 $\mathrm{nm}$, which corresponds to Na line. Also, the background emission is very low, which stated that the density of electrons in the plasma produced on the surface of the sample target is low as in the case of herbal medicine in Fig.-2. 
RASĀYAN J. Chem.

Vol. 13 | No. 2 |898 - 902| April - June | 2020

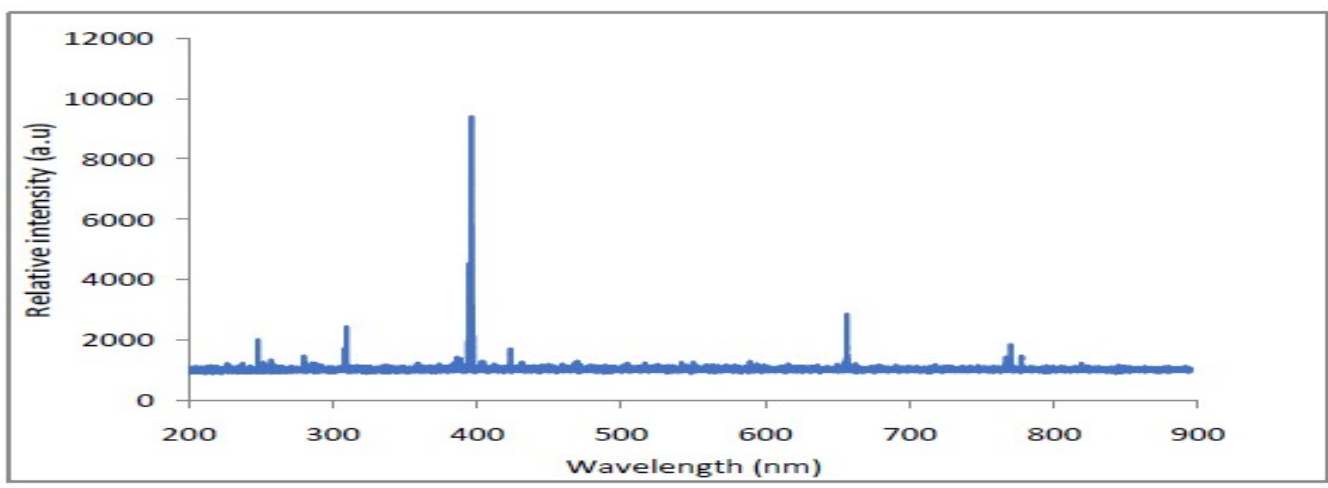

Fig.-2: Emission Spectrum Obtained From the Asam urat and Flu tulang Herbal Medicine.

Table-1: Atomic Lines Obtained From the Asam urat and Flu tulang Herbal Medicine.

\begin{tabular}{c|c|c|c}
\hline No & Elements & $\begin{array}{c}\text { Wavelengths } \\
(\mathrm{nm})\end{array}$ & $\begin{array}{c}\text { Relative Intensities } \\
(\text { a.u })\end{array}$ \\
\hline 1 & $\mathrm{C} \mathrm{(I)}$ & 247.8 & 2009 \\
\hline 2 & $\mathrm{Mg}(\mathrm{II})$ & 279.6 & 1463 \\
\hline 3 & $\mathrm{Al}(\mathrm{I})$ & 308.2 & 1728 \\
\hline 4 & $\mathrm{Fe}(\mathrm{I})$ & 309.2 & 2433 \\
\hline 5 & $\mathrm{Ca}(\mathrm{II})$ & 393.3 & 1957 \\
\hline 6 & $\mathrm{Al}(\mathrm{I})$ & 394.1 & 4551 \\
\hline 7 & $\mathrm{Al}(\mathrm{I})$ & 396.1 & 9401 \\
\hline 8 & $\mathrm{Ca}(\mathrm{II})$ & 396.8 & 2148 \\
\hline 9 & $\mathrm{Ca}(\mathrm{I})$ & 422.7 & 1706 \\
\hline 10 & $\mathrm{H}(\mathrm{I})$ & 656.3 & 2845 \\
\hline
\end{tabular}

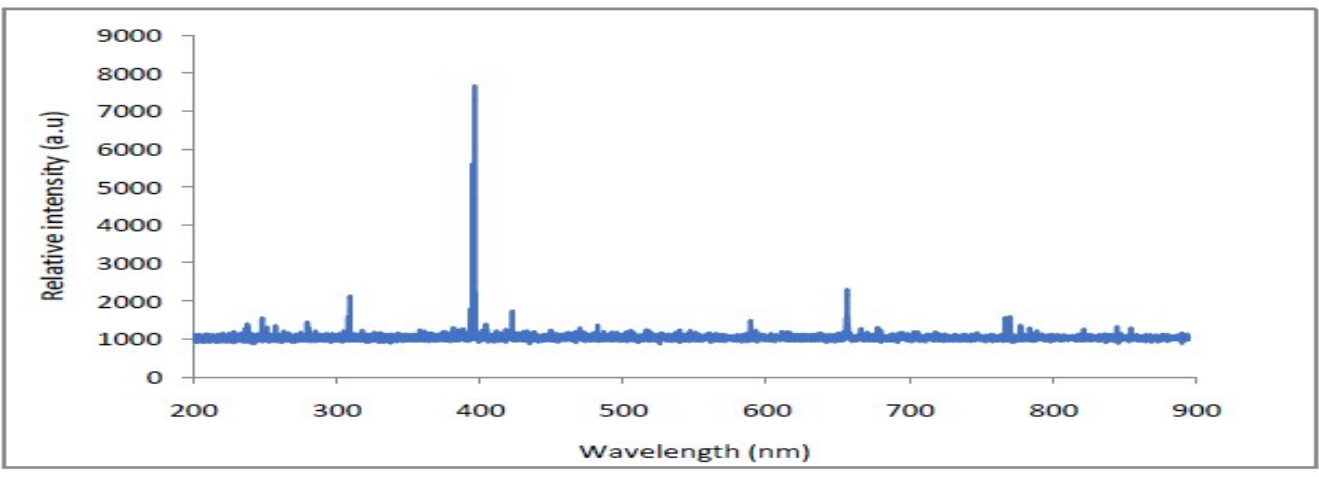

Fig.-3: Emission Spectrum Obtained From the Bunga naga Herbal Medicine

The composition of elements, their wavelengths and intensities obtained from the Bunga naga herbal medicine is summarized in Table- 2 .

Finally, the other spectroscopic technique of XRD was used to confirm the element identified by using $\mathrm{Nd}$ :YAG LIBS. To this end, only Ca element is identified as a representative of elements contained in the herbal medicine. Figure-4 shows the XRD spectrum obtained from (a) the Bunga naga, and (b) the Asam urat and Flu tulang herbal medicine. The spectrum shown in Fig. -4 shows muscovite crystal spectrum. Calcium is one of the elements in muscovite crystal. The muscovite crystal pattern obtained in Fig.- 4 is the same with the Crystallography Open Database as reported by Tomita et al. Therefore, spectrum obtained by XRD technique certified that the $\mathrm{Ca}$ element is confirmed as an element exists in herbal medicine, especially Asam urat and Flu tulang and Bunga naga herbal medicines. 
RASĀYAN J. Chem.

Vol. 13 | No. 2 |898 - 902| April - June | 2020

Table-2: Atomic Lines Obtained From the Bunga naga Herbal Medicine.

\begin{tabular}{c|c|c|c}
\hline No & Elements & $\begin{array}{c}\text { Wavelengths } \\
(\mathrm{nm})\end{array}$ & $\begin{array}{c}\text { Relative Intensities } \\
\text { (a.u) }\end{array}$ \\
\hline 1 & $\mathrm{C} \mathrm{(I)}$ & 247.8 & 1538 \\
\hline 2 & $\mathrm{Mg}(\mathrm{II})$ & 279.6 & 1433 \\
\hline 3 & $\mathrm{Al} \mathrm{(I)}$ & 308.2 & 1577 \\
\hline 4 & $\mathrm{Fe}(\mathrm{I})$ & 309.2 & 2120 \\
\hline 5 & $\mathrm{Ca}(\mathrm{II})$ & 393.3 & 1792 \\
\hline 6 & $\mathrm{Al}(\mathrm{I})$ & 394.1 & 5581 \\
\hline 7 & $\mathrm{Al}(\mathrm{I})$ & 396.1 & 7648 \\
\hline 8 & $\mathrm{Ca}(\mathrm{II})$ & 396.8 & 2172 \\
\hline 9 & $\mathrm{Ca} \mathrm{(I)}$ & 422.7 & 1733 \\
\hline 10 & $\mathrm{Na} \mathrm{(I)}$ & 589.1 & 1447 \\
\hline 11 & $\mathrm{H} \mathrm{(I)}$ & 656.3 & 2299 \\
\hline
\end{tabular}

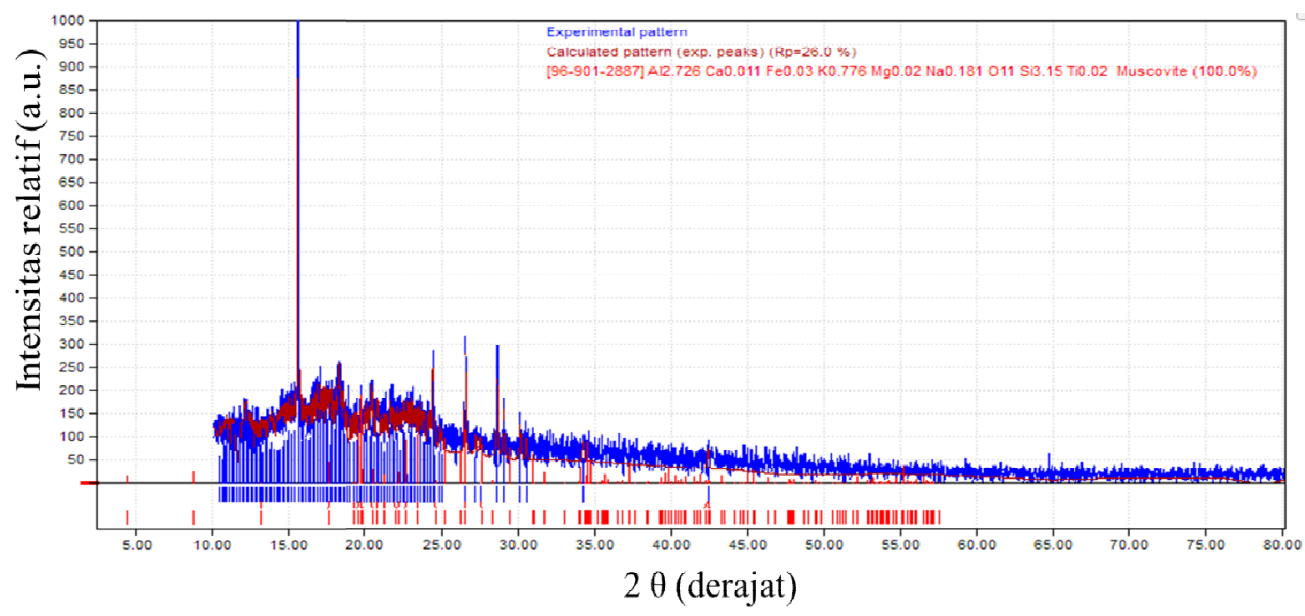

a

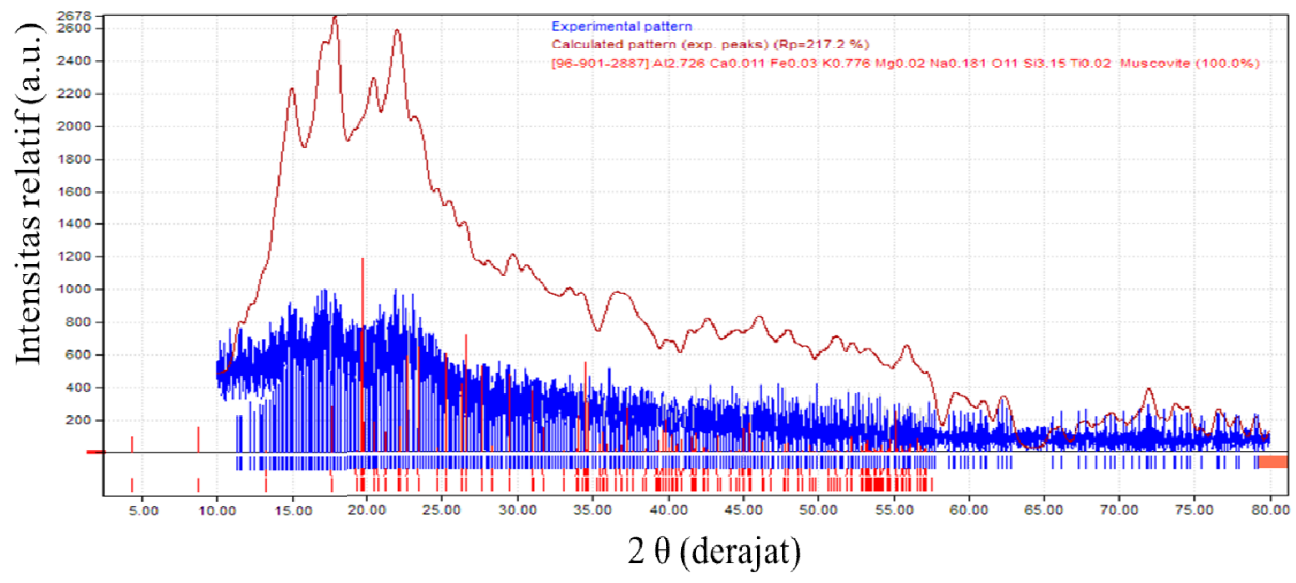

b

Fig.-4: XRD Emission Spectrum Obtained from (a) the Bunga naga, and (b) the Asam urat and Flu tulang Herbal Medicines

\section{CONCLUSION}

Rapid identification and analysis of major and minor elements in Indonesian herbal medicine have been successfully carried out using Nd:YAG LIBS technique. In this study, the Asam urat and Flu tulang and Bunga naga herbal medicine were used as sample targets. The laser-plasma was produced at a reduced 
RASĀYAN J. Chem.

Vol. 13 | No. 2 |898 - 902| April - June | 2020

pressure of $1333 \mathrm{~Pa}$ in the air surrounding gas. The result shows that major elements in herbal medicine such as $\mathrm{C}, \mathrm{Mg}, \mathrm{Al}, \mathrm{Fe}, \mathrm{Ca}$, and $\mathrm{H}$. Carbon (C) and $\mathrm{H}$ elements can successfully be detected both in the Asam urat and Flu tulang and Bunga Naga herbal medicines. Also, the other element of sodium (Na) has been identified from the Bunga Naga medicine. Calcium element contained in both herbal medicines and identified by using LIBS technique has been confirmed by using XRD technique. This results certified that the present LIBS technique can be employed to identify and analyze major and minor elements in herbal medicine.

\section{ACKNOWLEDGMENT}

This study was financially supported by LPPM Diponegoro University Indonesia with project No. 831.1 02/UN7.P4.3/PP/2019.

\section{REFERENCES}

1. A. Ghani, A. Zulfaqar, M. Ishtiaq, M. Mehwish and P. Saira, African Journal of Biotechnology, 11(78), 14386 (2012), DOI:10.5897/AJB12.762

2. Y. Qing-hua, I. Yang, Q. Wang, and X. Ma, Journal Saudi Chemical Society, 16, 287 (2011), DOI: $10.1016 /$ j.jscs.2011.01.014

3. N. R. Bader, Rasayan J. Chem., 4, 49 (2011)

4. R. Shirdama, Z. Modarres-Tehrani, F. Dastgoshadeh, Rasayan Journal of Chemistry, 1, 757 (2008)

5. D.A. Cremers, L.J. Radziemski, Handbook of Laser-induced Breakdown Spectroscopy, John Wiley \& Sons Ltd, New York (2006).

6. A. Khumaeni, Z. S. Lie, H. Niki, K. H. Kurniawan, T.T. Lie, Y.I. Lee, K. Kurihara, Y. Deguchi, K. Kagawa, Analytical and Bioanalytical Chemistry. 400(10), 3279 (2011), DOI: 10.1007/s00216-0114801-1

7. A. Khumaeni, Z.S. Lie, K.H. Kurniawan, K. Kurihara, K. Kagawa, Journal of Modern Optics. 65, 2229 (2018), DOI:10.1080/09500340.2018.1506053

8. J. P. Singh, S.N. Thakur, Laser-induced Breakdown Spectroscopy, Elsevier, Oxford, 2007.

[RJC-5592/2019] 